Dartmouth Medical School by Joanne Lynd and Joan Teno, has suggested that widespread use of advance directives, in the wake of the Patient SelfDetermination Act, has had little effect on patient satisfaction or clinical practice. The only statistically significant difference found so far is that advance directives are more likely to be recorded in patient notes. And fewer than fifteen per cent of Americans have signed advance directives. Many physicians actually find it more difficult to stop prolonged treatment than they did twenty years ago, despite the advent of advance directives. Doctors have more options and may fear malpractice suits if they fail to make full use of available technologies - or they may simply be uncertain about when to invoke the advance directive. When is the patient with a chronic disease actually $d y i n g$ ?

Callahan is adamant about the need for legal procedures to curb long drawn-out deaths at the mercy of interventionist technology. But he urges us not to stop there. 'The old question was: when is a patient dying, and thus a candidate for the abatement of lifesaving treatment? The new question should be: at what point, or within what range, should lifesaving treatment be abated to enhance the likelihood of a good death?'

As in his controversial Setting Limits, which put forward some unpopular propositions about rationing health care for the elderly, Callahan's calm style masks what is a radical proposition in the American context, although perhaps not in the British hospice movement. This is that the correct aim of care for the terminally ill should be to ensure a positively 'good death', not merely to avoid a bad one. Medicine needs to work backward from the ideal of death at the right time and right circumstances, rather than in its characteristic forward-only mode towards cure.

'Active treatment to cure disease and prevent death would stop well short of its technical possibilities, at the point where a peaceful death could be most assured and best managed. The worry that a patient might die sooner than technologically necessary would be effectively balanced by anxiety that a patient might die later than was compatible with a peaceful death.'

This is what the patient needs, Callahan argues; what the physician needs is a corresponding lightening of obligation. Withdrawing care does not equate to killing the patient, because it is 'the inexorable forces of nature' which kill. To think otherwise is to fall victim to "technological monism": 'the tendency to erase the difference between human action as a cause of what happens in the world, and independent, natural biological processes, those old-fashioned causes of disease and death. It is nothing less than an ingenious way of blaming the victim, as if death itself were now our fault, the result of human choices, not the independent workings of nature.'

A caveat is in order here. Unlike some of the more starry-eyed 'natural death' advocates, Callahan is careful not to romanticise old ways of dying. 'Death is not, and should not become, a glorious event to be sought and embraced. It is an evil. It ruptures the solidarity of the human community. It forces the dying person out of the lives of those around her, a loss both to her and to others. The source of the evil is the "savagery of nature", a nature to be accepted but not romanticized.' Nor can we ever recapture whatever it was that allowed the Confederate soldier to die so well. Reviving defunct rituals is a sort of mauvaise foi. 'Since no one else can give us, as if it were our own, a meaning to our dying and death, we must find that for ourselves; some of us will never find it.'

Whether death is bad, let alone evil, may be a matter for scepticism. In the ancients' view, the final nothingness was neutral. But these passages demonstrate the enticing combination of fervour and sensitivity which pervades the whole of The Troubled Dream of Life. Avoiding portentousness and pretentiousness, Callahan writes for the lay person, assuming no philosophical knowledge and little clinical background. Yet in a field which invites home-spun philosophising and high-flown cliché, his thought and prose remain beautifully spare and clean.

Callahan's sensitive and careful analysis is most apposite to rightsminded American society, where technology gallops ahead and the establishment of hospices proceeds in more tortoise-like fashion. There is a risk that $\mathrm{UK}$ readers may seize on Callahan's second thoughts about choice and control for dying people as evidence that the Americans have finally seen the error of their litigious ways. Such complacency would be small-minded and misguided. Callahan's wise book could enable this country to achieve a compromise which is something other than fudge.
DONNA DICKENSON

Senior Lecturer,

Department of Health and Social

Welfare,

The Open University,

Milton Keynes

\section{Living with AIDS: experiencing ethical problems}

Miriam E Cameron, Newbury Park, SAGE Publications, 1993, 251 pages, $£ 15.50$ sc

This book is based on the author's doctoral study in which she interviewed people with AIDS and their significant others. In most of it, with sections for each of the major ethical issues, she sets out verbatim the views of these very diverse people, with a few context-setting comments. She concludes each section with her own comments and analysis. The book is framed by chapters setting out her approach to ethics and the problems raised by AIDS. A particularly thoughtful section outlines the ethical dilemmas she herself faced and resolved during the course of the work.

The author somewhat self-consciously sets out her stall for an approach based in descriptive ethics, contrasting this with other more familiar and perhaps more detached systems. The issues covered in the various chapters include substance misuse, chronic disease, death, discrimination, money, health care, personhood, relationships and sexuality. The book is lightly peppered with some rather distracting and generally unhelpful figures, either comprising histograms showing the variety of her subjects or some curious diagrams, laden with words, to illustrate ethical issues in a structural way.

Despite the familiarity of the issues, the voices of those affected come through very strongly in a way that ensures that the book's approach to ethics is deeply rooted in the real world of ordinary, and at the same time extraordinary, people. The author's commentaries at the end of each chapter are rather variable: they mingle some very insightful comments with some surprisingly banal interpretations and trite, sometimes frankly unrealistic, solutions. Perhaps she should have had more confidence in the ability of the voices to convey the problems and the difficulty of 
reaching universal solutions more implicitly. On the other hand, her evident empathy for, and involvement with, her interviewees are exemplary, whether as a health care professional (she has a nursing background) or as a social scientist.

The book overall is a very interesting way of projecting some of the multitude of personal and social ethical issues arising out of the AIDS pandemic, from a North American standpoint; many of the issues travel well, however. The author's skilful eliciting and selection of these simple and direct expressions of the human conflicts arising from this epidemic will be thought-provoking for people who want to understand it better, whether they are familiar with the issues or not and whether they are health care workers, ethicists or lay people.

PROFESSOR ANTHONY J PINCHING

Professor of Immunology,

Medical College of St Bartholomew's

Hospital,

West Smithfield,

London EC1A 7BE, UK.

\section{Ethics in obstetrics and gynecology}

Edmund D Pellegrino and David C Thomasma, Oxford and New York, Oxford University Press, 1994, 278 pages, $£ 30.00$

\section{Human in vitro fertilisation: a case study in the regulation of medical innovation}

\author{
J Gunning and V English, Aldershot \\ and Vermont, Dartmouth Publishing \\ Co, 1993, 219 pages, $£ 35.00$
}

The area of reproductive medicine is one of particular importance for ethics, because the arrangements surrounding sex and reproduction have always been central to social order and convention, and are often surrounded with mystique, taboo and religious and social significance.

In most societies, family, household and kinship relations are all bound up with these basic biological functions, and these, of course, are the underpinning of economic and ultimately political order. So the serious treatment of these issues in relation to recent scientific innovation in reproductive technology is to be welcomed.

Ethics in Obstetrics and Gynecology is a helpful book for those working in these areas, addressing itself essentially to professionals, but also of interest to the concerned general reader. In addition, it will be a useful source of comment and argument for those whose main interest is in the legal aspects, and although written within the context of American law, the principles involved are of equal interest to European and British legal theorists, who are also under a pressing necessity to reach consensus on a number of contentious issues in the area of reproductive medicine.

The book covers a wide range of topics including contraception and abortion, embryo selection and destruction, IVF and surrogacy, prenatal diagnosis and its consequences, HIV infection, uterine cancer, the premature infant, and issues surrounding childbirth itself, including the controversial issue of court-ordered caesarean deliveries.

The conflict that some of these issues generate between the patient and the person responsible for his/her health-care is a central focus for the authors, who recommend as a solution prevention and, where this is impossible, techniques of crisis management based on a virtues approach. This is in contrast to the more familiar approach which has become current in medical ethics literature, where a utilitarian ethic is set against a morality of inflexible principles, and the student is left with the impression that there is no ethical certainty - that relativism rules. Pellegrino and Thomasma argue for rather more conviction than this, proposing and seeking to justify a framework for ethical medicine based on the virtues of self-effacement, self-sacrifice, compassion and integrity. Underlying these are the broader ethical principles of beneficence and respect for autonomy.

Where a number of philosophers writing on the subject, in particular, of abortion, have taken up a position with very serious practical implications on the basis of abstract discussion of the notion of personhood, these authors who, perhaps because they represent a fruitful collaboration between a medical ethicist and a practitioner who is in day-to-day contact with patients, take seriously the concept of the fetus as a patient - and thus an object of moral concern. The interests and involvement of other family members too, in particular $\stackrel{\text { ? }}{\text {. }}$ fathers, are also given a weight that $\overrightarrow{\overrightarrow{\vec{B}}}$ they have conspicuously failed to be granted in the current literature.

Human in Vitro Fertilisation has more limited aims. Written primarily with $\frac{\bar{\sigma}}{\partial}$ UK interests in mind, but providing a useful summary of the legal position in various other countries, it records the $\infty$ ethical debate surrounding the devel- $\overrightarrow{0}$ opment of IVF technology from the $\overrightarrow{-}$ earliest researches of Robert Edwards, $\vec{\omega}$ Patrick Steptoe and others, to the birth of Louise Brown in Oldham in 1978, $\overline{\mathrm{D}}$ and beyond this to controversies gener- iv ated by the latest reproductive tech- $\vec{\omega}$ nologies. This throws an interesting light on the extent to which current $\infty$ practices have gone far beyond what the original pioneers believed would be ethically permissible.

The authors document the setting $\subseteq$ up of ethical bodies in both the USA $\overparen{D}$ and Britain, and interestingly record $\vec{C}$ one of the earliest submissions of $f$ Edwards to the USA Ethics Advisory Board in which he wrote: 'We feel strongly that any ethical decision about such work should be the responsibility of the patient, the doctor and the funding organization' 응 (page 18).

This notion that these were private decisions has long been abandoned, as 3 the public implications of private decisions have become apparent. Gunning and English have supplied a text which documents this shift, in par- $\vec{D}$ ticular describing the creation of the $\bar{\sigma}$ Voluntary Licensing Authority in Britain, the reasons for the commissioning of the Warnock Report, and 3 subsequent legislative concerns and $O$ developments.

Readers of both these volumes will $\frac{D}{2}$ gain a broader and more informed view of many important issues which $\mathrm{N}$ have yet to be resolved.

\section{BRENDA ALMOND Nิ Department of Philosophy, $\sigma$ University of Hull}

\section{Xenotransplantation}

Edited by Dr C Cooper, E Kemp, K Reemtsma and D J G White, Berlin, Springer-Verlag, 1991, 555 pages, DM420 hb

This book addresses the issue of trans- $\delta$ plantation of organs between species with the purpose of saving humance lives by sacrificing animals. 